\title{
Severe early onset retinitis pigmentosa in a Moroccan patient with Heimler syndrome due to novel homozygous mutation of PEX1 gene.
}

DOI:

10.1016/j.ejmg.2016.09.004

\section{Document Version}

Accepted author manuscript

Link to publication record in Manchester Research Explorer

Citation for published version (APA):

Ratbi, I., Jaouad, I. C., Elorch, H., Alsheqaih, N., Elalloussi, M., Lyahyai, J., Berraho, A., Newman, W., \& Sefiani, A. (2016). Severe early onset retinitis pigmentosa in a Moroccan patient with Heimler syndrome due to novel homozygous mutation of PEX1 gene. European journal of medical genetics, 59(10), 507-511.

https://doi.org/10.1016/j.ejmg.2016.09.004

\section{Published in:}

European journal of medical genetics

\section{Citing this paper}

Please note that where the full-text provided on Manchester Research Explorer is the Author Accepted Manuscript or Proof version this may differ from the final Published version. If citing, it is advised that you check and use the publisher's definitive version.

\section{General rights}

Copyright and moral rights for the publications made accessible in the Research Explorer are retained by the authors and/or other copyright owners and it is a condition of accessing publications that users recognise and abide by the legal requirements associated with these rights.

\section{Takedown policy}

If you believe that this document breaches copyright please refer to the University of Manchester's Takedown Procedures [http://man.ac.uk/04Y6Bo] or contact uml.scholarlycommunications@manchester.ac.uk providing relevant details, so we can investigate your claim.

\section{OPEN ACCESS}




\section{Accepted Manuscript}

Severe early onset retinitis pigmentosa in a Moroccan patient with Heimler syndrome due to novel homozygous mutation of PEX1 gene

Ilham Ratbi, Imane Cherkaoui Jaouad, Hamza Elorch, Nada Al-Sheqaih, Mustapha

Elalloussi, Jaber Lyahyai, Amina Berraho, William G. Newman, Abdelaziz Sefiani

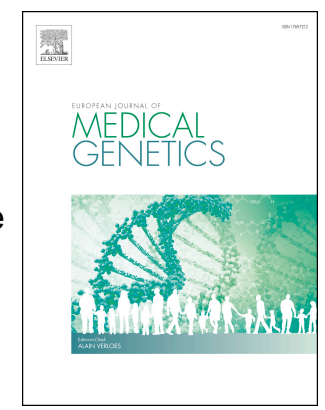

PII:

S1769-7212(16)30306-8

DOI:

10.1016/j.ejmg.2016.09.004

Reference: $\quad$ EJMG 3201

To appear in: European Journal of Medical Genetics

Received Date: 9 September 2016

Accepted Date: 11 September 2016

Please cite this article as: I. Ratbi, I.C. Jaouad, H. Elorch, N. Al-Sheqaih, M. Elalloussi, J. Lyahyai, A. Berraho, W.G. Newman, A. Sefiani, Severe early onset retinitis pigmentosa in a Moroccan patient with Heimler syndrome due to novel homozygous mutation of PEX1 gene, European Journal of Medical Genetics (2016), doi: 10.1016/j.ejmg.2016.09.004.

This is a PDF file of an unedited manuscript that has been accepted for publication. As a service to our customers we are providing this early version of the manuscript. The manuscript will undergo copyediting, typesetting, and review of the resulting proof before it is published in its final form. Please note that during the production process errors may be discovered which could affect the content, and all legal disclaimers that apply to the journal pertain. 


\section{Severe early onset retinitis pigmentosa in a Moroccan patient with Heimler syndrome due to novel homozygous mutation of PEX1 gene.}

\section{Running title : Moroccan patient with Heimler syndrome}

Ilham Ratbi a, b, ", Imane Cherkaoui Jaouad ${ }^{\text {a, b }}$, Hamza Elorch ${ }^{\text {c }}$, Nada Al-Sheqaih ${ }^{\text {d, e }}$, Mustapha Elalloussi ${ }^{\dagger}$, Jaber Lyahyai ${ }^{a}$, Amina Berraho ${ }^{c}$, William G. Newman ${ }^{d,}$ e, Abdelaziz Sefiani $^{\text {a, b }}$

${ }^{a}$ Centre de génomique humaine, Faculté de médecine et pharmacie, Mohammed $\mathrm{V}$ University in Rabat, 10100, Morocco

b Département de génétique médicale, Institut National d'Hygiène, BP 769 Agdal, 10090 Rabat, Morocco

${ }^{c}$ Service d'Ophtalmologie B, Hôpital des Spécialités, CHU Rabat, Morocco

d Manchester Centre for Genomic Medicine, St. Mary's Hospital, Manchester Academic Health Sciences Centre, Manchester M13 9WL, UK

e Manchester Centre for Genomic Medicine, Institute of Human Development, University of Manchester, Manchester M13 9WL, UK

${ }^{\dagger}$ Departement de Pédodontie-Prévention, Faculté de Médecine Dentaire, Université Mohammed V, BP 6212 Madinat Al Irfane, 10100 Rabat, Morocco

\section{* Corresponding author:}

Ilham RATBI, Département de génétique médicale, Institut National d'Hygiène, BP 769 Agdal, 10090 Rabat, Morocco. Tel. +212 613586 797; Fax. +212 537772 067; E-mail. i.ratbi@um5s.net.ma 


\section{Abstract}

Heimler syndrome (HS) is a rare recessive disorder characterized by sensorineural hearing loss (SNHL), amelogenesis imperfecta, nail abnormalities, and occasional or late-onset retinal pigmentation. It is the mildest form known to date of peroxisome biogenesis disorder caused by hypomorphic mutations of PEX1 and PEX6 genes. We report on a second Moroccan family with Heimler syndrome with early onset, severe visual impairment and important phenotypic overlap with Usher syndrome. The patient carried a novel homozygous missense variant c.3140T>C (p.Leu1047Pro) of PEX1 gene. As standard biochemical screening of blood for evidence of a peroxisomal disorder did not provide a diagnosis in the individuals with HS, patients with SNHL and retinal pigmentation should have mutation analysis of $P E X 1$ and PEX6 genes.

Keywords : Heimler syndrome, Moroccan, retinitis pigmentosa, PEX1, variant. 


\section{Introduction}

Heimler syndrome (OMIM: 234580) was first reported in 1991 in two siblings of a healthy non-consanguineous couple with sensorineural hearing loss (SNHL), enamel hypoplasia, and nail abnormalities (Heimler et al., 1991). Subsequent reports confirmed the phenotypic features of the condition (Tischkowitz et al., 1999; Pollak et al., 2003; Ong et al., 2006). In a follow up assessment of the originally described case macular dystrophy and retinal pigmentation were noted (Lima et al., 2011). Using a whole exome sequencing approach, we recently identified biallelic mutations in the PEX1 and PEX6 genes in six families with Heimler syndrome. Each family was characterised by at least one hypomorphic allele that results in mild peroxisomal dysfunction (Ratbi et al., 2015). These findings define Heimler syndrome as the mildest form of peroxisome biogenesis disorder (PBD). Here we report the clinical and molecular data of a second Moroccan family with Heimler syndrome with early onset, severe visual impairment and important phenotypic overlap with Usher syndrome (OMIM: 276901).

\section{Clinical report}

We investigated a thirteen year old girl years old girl of Moroccan origin, the third child of a healthy consanguineous couple (first cousins). Her siblings were unaffected. She presented with bilateral severe SNHL at eight months confirmed on auditory evoked potential measurement. This resulted in an inability to acquire normal speech. At 14 months, she had an abnormal bilateral smooth pursuit test with rotary nystagmus. Ophthalmic examination under general anesthesia showed a normal anterior segment with normal intraocular pressure. Fundoscopic exam revealed pigmented deposits, slender and rigid retinal arteries and a pale yellow 
waxy papilla consistent with retinitis pigmentosa. At 3 years old, the parents noticed decreased night vision (nyctalopia). The electroretinogram was consistent with a bilateral retinal disorder affecting both the rods and cones with low voltage traces under white and red flashes stimulation, more pronounced in the right eye (Fig. 1a). Visual evoked potentials were within the normal range. There was a rapid and important decrease of visual acuity difficult to assess because of communication disorders. In her most recent assessment at 12 years old, fundoscopic examination revealed decreased macular reflection with edema and persistance of pigmented deposits in the retinal periphery (Fig. 1b). Optical coherence tomography (OCT) showed bilateral cystoid macular edema with a macular central thickness of $506 \mu \mathrm{m}$ on the right and $507 \mu \mathrm{m}$ on the left (normal is $330 \mu \mathrm{m}$ ) (Fig. 1c). She was treated with acetazolamide $250 \mathrm{mg}$ for two weeks, without any significant amelioration of the macular edema. Subsequent treatments with intravitreal triamcinolone acetonid and intravitreal anti-VEGF (ranibizumab) did not lead to resolution of the edema. Dental examination and orthopantogram showed hypoplastic teeth and amelogenesis imperfecta with a yellow-brownish coloration, rough square-shaped crowns, and lack of contact between adjacent teeth. She had severe caries affecting the secondary dentition, whereas her primary dentition was normal (Fig. 2). She did not have any nail defects, neurological symptoms or other health problems.

In the light of our recent description of visual phenotypes in many patients with Heimler syndrome (Ratbi et al., 2015), and the features of amelogenesis imperfecta and SNHL, we considered this diagnosis. Blood samples from the proband and her parents were collected after written informed consent (UK NHS Ethics Reference 11/H1003/3). DNA was isolated using standard techniques (Miller et al., 1988). Molecular genetic testing of the entire coding region and flanking introns of PEX1 
and PEX6 was undertaken by complete Sanger sequence analysis (details available on application). This led to the identification of a novel homozygous missense variant c.3140T>C (p.Leu1047Pro) in PEX1 (Accession number : 0000116002). Sequencing of PEX6 was normal. Both parents were heterozygous for the variant (Fig.3a ; Fig. 3b). The novel variant was not present in in-house databases of $>800$ exomes, including 40 Moroccan exomes nor in public databases namely the 1,000 genome database, the Exome Variant Server and the Exome Aggregation Consortium. The leucine at position 1047 is highly conserved. In silico prediction programmes MutationTaster, SIFT and Polyphen-2 considered that the variant was pathogenic.

\section{Discussion}

Human peroxisome biogenesis disorders or Zellweger syndrome spectrum (PBD, ZSS) are a heterogeneous group of autosomal recessive disorders comprising four clinically distinct subtypes: the Zellweger syndrome (OMIM: 614872), neonatal adrenoleukodystrophy (OMIM: 601539), infantile Refsum disease (OMIM: 601539) and rhizomelic chondrodysplasia punctata (OMIM: 215100), which is not necessarily more slowly progressive than Zellweger (Zeharia et al., 2007; Regal et al., 2010; Ebberink et al., 2011). These conditions are characterized by a wide phenotypic pleiotropy, including leukodystrophy, developmental delay, seizures, peripheral neuropathy, SNHL, retinopathy, skeletal and craniofacial abnormalities and other organ damage (liver, heart, kidneys) (Braverman et al., 2013). Clinical manifestations are variable from severe, early-childhood lethal Zellweger syndrome to milder more slowly progressive phenotypes in rhizomelic chondroplasia punctata (Motley et al., 2002; Ebberink et al., 2011). Recently, we defined Heimler syndrome, a rare autosomal recessive disorder characterized by SNHL, enamel hypoplasia of the 
secondary dentition, and nail abnormalities as a fifth clinical subtype of PBD, and the mildest form recognized to date. The diagnosis of PBD can be determined by biochemical assays. Biochemical abnormalities detected in blood and/or urine should be confirmed in cultured fibroblasts. Measurement of plasma very-long-chain fatty acid (VLCFA) levels is the most commonly used and most informative initial screen. Elevation of C26:0 and C26:1 and the ratios C24/C22 and C26/C22 are consistent with a defect in peroxisomal fatty acid metabolism. The degree of VLCFA plasma concentration elevation may vary, with a small percentage of individuals demonstrating only modest increases (Wanders et al., 2005). Where screening analyses of blood have been undertaken biochemical evidence of a PBD has been lacking in patients with Heimler syndrome (Ratbi et al., 2015).

In this study, we report the identification of a novel homozygous missense variant c.3140T>C (p.Leu1047Pro) of PEX1 in a girl with Heimler syndrome. In three previously reported caucasian families with Heimler syndrome due to PEX1 mutations, compound heterozygosity for a previously reported loss of function and a novel missense PEX1 variant was described (Ratbi et al., 2015) (Fig 3b). The patient reported here was homozygous for a novel hypomorphic PEX1 allele similar to that reported in another Moroccan family PEX1 (p.Trp1250*).

The features of SNHL and retinitis pigmentosa, overlap with the heterogeneous disorder Usher syndrome (OMIM: 276900). Although amelogenesis imperfecta discriminates between the two conditions this does not become apparent until the eruption of the secondary dentition. Retinal pigmentation is an inconsistent feature of Heimler syndrome. Among the 14 patients from six families investigated by Ratbi et al., ocular assessment was reported in 12. Seven patients between 16 and 31 yearsold had isolated retinal pigmentation. In the two oldest described patients (29 and 31 
years-old) there was also macular dystrophy. The new case reported here had an early onset (decreased night vison at 3 years-old) and severe retinitis pigmentosa.

Because of the SNHL and retinal pigmentation, Heimler syndrome is an important differential diagnosis for Usher syndrome. As standard biochemical screening of blood for evidence of a peroxisomal disorder does not provide a diagnosis in Heimler syndrome (Ratbi et al., 2015), patients with SNHL and retinal pigmentation should have mutation analysis of PEX1 and PEX6.

In summary, we report the second Moroccan case of Heimler syndrome due to hypomorphic PEX1 variants. The severe ocular features of retinal pigmentation and macular dystrophy with SNHL indicate that Heimler syndrome is a major differential diagnosis of Usher syndrome. Here genetic testing allowed us to provide an accurate diagnosis and precise genetic counseling to the family. 


\section{Acknowledgments}

We thank the patient and his family. The authors would like to thank the Exome Aggregation Consortium and the groups that provided exome variant data for comparison. A full list of contributing groups can be found at http://exac.broadinstitute.org/about. 
Accession number : 0000116002 


\section{Web Resources}

The URLs for data presented herein are as follows:

OMIM, http://www.omim.org/

1000 Genomes, http://www.1000genomes.org/

Exome Variant Server, http://evs.gs.washington.edu/EVS/

Exome Aggregation Consortium (ExAC) Browser, http://exac.broadinstitute.org

ANNOVAR, http://www.openbioinformatics.org/annovar/

MutationTaster, http://www.mutationtaster.org/

SIFT, http://sift.jcvi.org/

Polyphen-2, http://genetics.bwh.harvard.edu/pph2/ 


\section{Figure titles and legends}

\section{Figure 1 : Ocular features.}

a: Electroretinogram at 3 years-old showing bilateral retinal disorder affecting both rods and cones with low voltage trace under white and red flash stimulation, more pronounced in the right eye.

b: Retinal photograph of the patient at 12 years showing pigmented deposits in the retinal periphery.

c: Optical coherence tomography (OCT) of the patient aged 12 years showing bilateral cystoid macular edema with a macular central thickness.

$\mathrm{LE}=$ left eye ; RE=right eye.

\section{Figure 2 : Dental abnormalities.}

Clinical appearance of teeth and orthopantogram of the patient at 10 years showing severe amelogenesis imperfecta.

\section{Figure 3 : Pedigree and molecular analysis report of the studied family.}

a: Pedigree of the family. Squares are males, circles are females, the double line between individuals indicates consanguinity. Affected individual (II:3) is shaded and indicated by an arrow.

b: Electropherograms of identified novel PEX1 mutation. The patient (II:3) is homozygous for c.3140T>C in PEX1 and both parents are heterozygotes (I:1 and l:2).

c: Schematic view of the PEX1 gene structure, protein domains, and localization of identified PEX1 mutations in Heimler syndrome patients. The mutations reported 
were indicated with green frame (Ratbi et al., 2015). The mutation identified in this study was indicated with red frame. 


\section{References}

Braverman, N.E., D’Agostino, M.D., Maclean, G.E., 2013. Peroxisome biogenesis disorders:Biological, clinical and pathophysiological perspectives. Dev. Disabil. Res. Rev. 17, 187-196.

Ebberink, M.S., Mooijer, P.A., Gootjes, J., Koster, J., Wanders, R.J., Waterham, H.R., 2011.Genetic classification and mutational spectrum of more than 600 patients with a Zellweger syndrome spectrum disorder. Hum. Mutat. 32, 59-69.

Heimler, A., Fox, J.E., Hershey, J.E., Crespi, P., 1991. Sensorineural hearing loss, enamel hypoplasia, and nail abnormalities in sibs. Am. J. Med. Genet. 39, 192-195.

Lima, L.H., Barbazetto, I.A., Chen, R., Yannuzzi, L.A., Tsang, S.H., Spaide, R.F., 2011. Macular dystrophy in Heimler syndrome. Ophthalmic Genet. 32, 97-100.

Miller, S.A., Dykes, D.D., Polesky, H.F., 1988. A simple salting out procedure for extracting DNA from human nucleated cells. Nucleic Acids Res. 16,1215.

Motley, A.M., Brites, P., Gerez, L., Hogenhout, E., Haasjes, J., Benne, R., et al., 2002. Mutational spectrum in the PEX7 gene and functional analysis of mutant alleles in 78 patients with rhizomelic chondrodysplasia punctata type 1. Am. J. Hum. Genet. 70, 612-624.

Ong, K.R., Visram, S., McKaig, S., Brueton, L.A., 2006. Sensorineural deafness, enamel abnormalities and nail abnormalities: a case report of Heimler syndrome in identical twin girls. Eur. J. Med. Genet. 49,187-193.

Pollak, C., Floy, M., Say, B., 2003. Sensorineural hearing loss and enamel hypoplasia withsubtle nail findings: another family with Heimler's syndrome. Clin. Dysmorph. 12, 55-58.

Ratbi, I., Falkenberg, K.D., Sommen, M., Al-Sheqaih, N., Guaoua, S., Vandeweyer, G., et al.,2015. Heimler syndrome is caused by hypomorphic mutations in the peroxisome-biogenesis genes PEX1 and PEX6. Am. J. Hum. Genet. 97, 535-545.

Regal, L., Ebberink, M.S., Goemans, N., Wanders, R.J., De Meirleir, L., Jaeken, J., et al., 2010. Mutations in PEX10 are a cause of autosomal recessive ataxia. Ann.

Neurol. 68, 259-263.

Tischkowitz, M., Clenaghan, C., Davies, S., 1999. Amelogenesis imperfecta, sensorineural Hearing loss, and Beau's lines: a second case report of Heimler's syndrome. J. Med. Genet. 36, 941-943.

Wanders, R.J., Waterham, H.R., 2005. Peroxisomal disorders I: biochemistry and genetics of peroxisome biogeesis disorders. Clin. Genet. 67, 107-133.

Zeharia, A., Ebberink, M.S., Wanders, R.J., Waterham, H.R., Gutman, A., Nissenkorn, A., et al., 2007. A novel PEX12 mutation identified as the cause of a peroxisomal biogenesis disorder with mild clinical phenotype, mild biochemical 
abnormalities in fibroblasts and a mosaic catalase immunofluorescence pattern, even at 40 degrees C. J. Hum. Genet. 52, 599-606. 

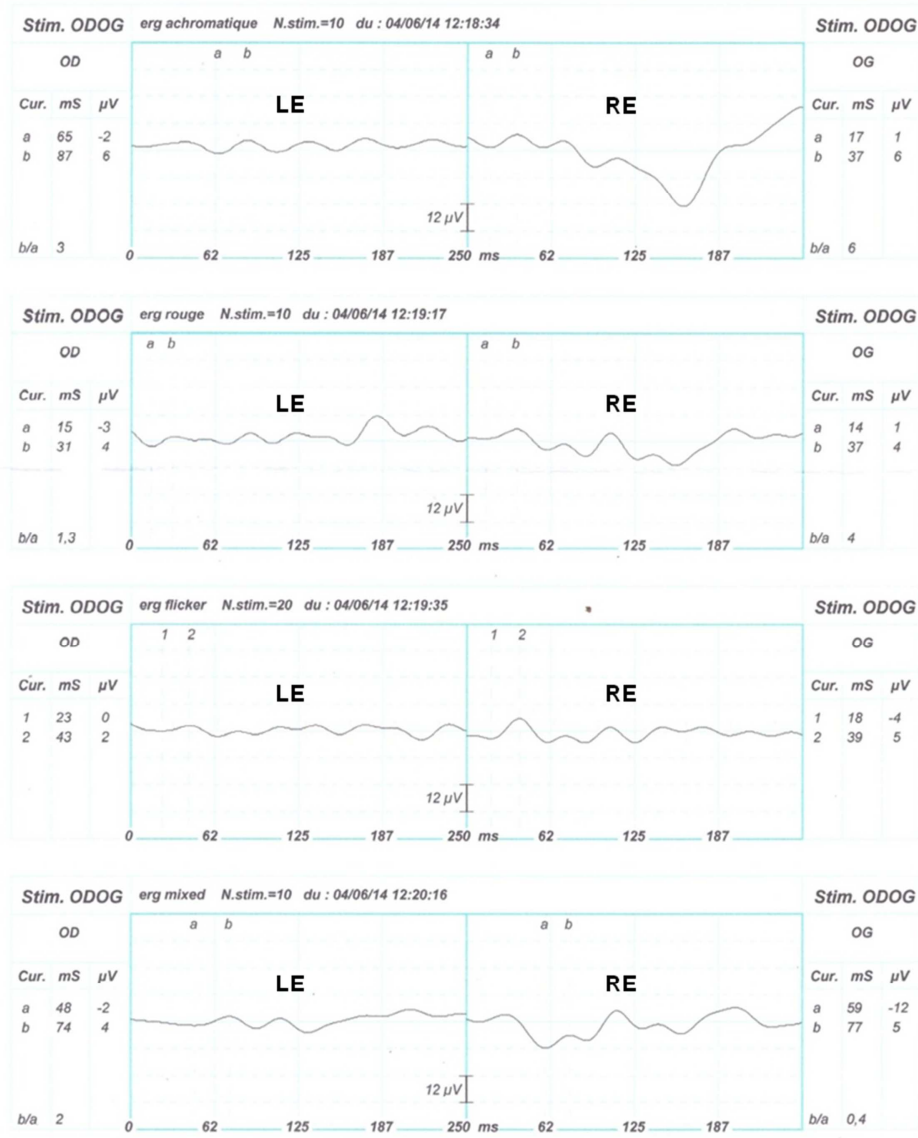

\section{a}
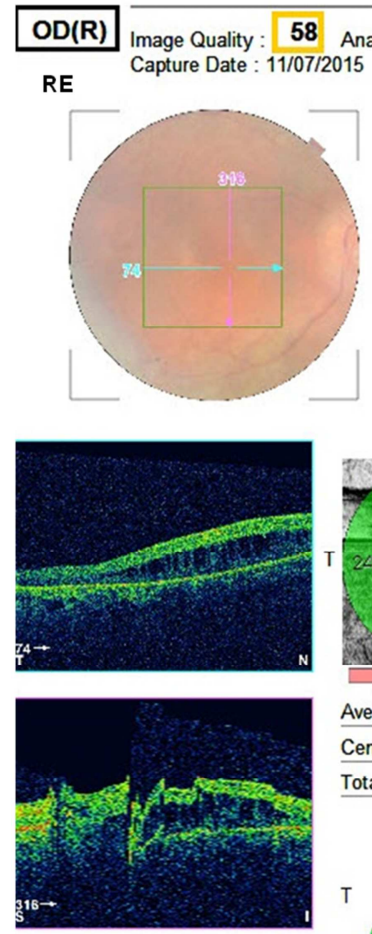

C
Retinal thickness map ILM - RPE / Red-free

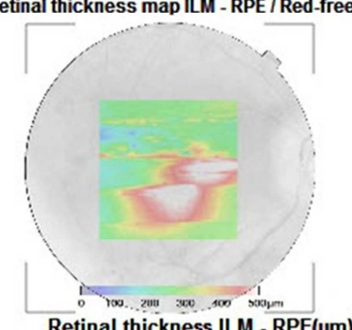

Retinal thickness ILM - RPE( $\mu \mathrm{m})$

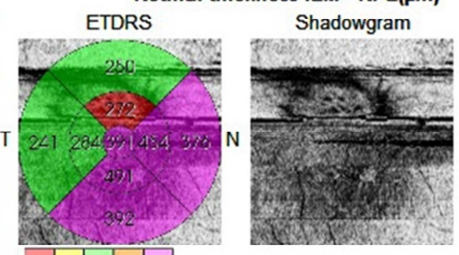

$\begin{array}{lll}1 & 1\end{array}$

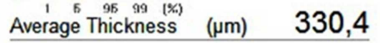

Center Thickness $\quad(\mu \mathrm{m}) \quad 404$

Total Volume $\quad\left(\mathrm{mm}^{3}\right) \quad 9,34$

$\begin{array}{cc}\text { ILM - RPE Map } & \text { RPE Surface } \\ \mathrm{S} & \mathrm{S}\end{array}$

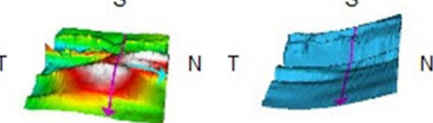

\# VisioSystem

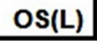

LE

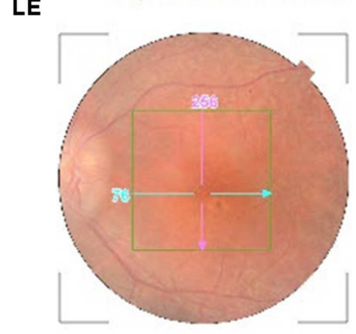

Retinal thickness map ILM - RPE / Red-free
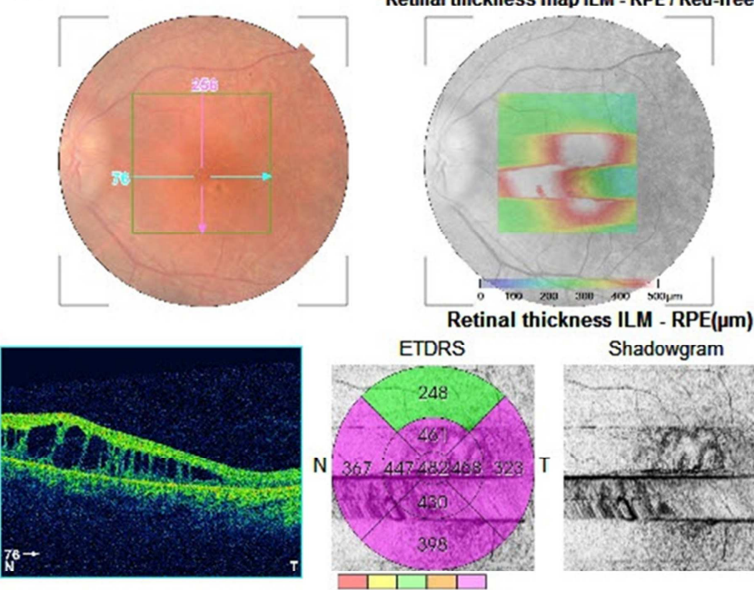
ETDRS
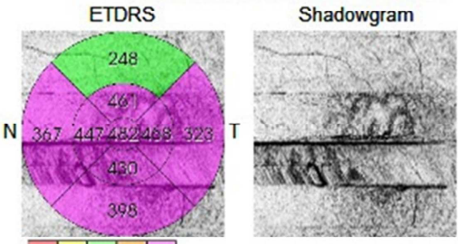

I I I I

\begin{tabular}{lll}
15 & $55^{99}$ \\
Average Thickness & $(\mu \mathrm{m}) \quad 363,7$ \\
\hline
\end{tabular}

\begin{tabular}{lll} 
Center Thickness $\quad(\mu \mathrm{m}) \quad 486$ \\
\hline
\end{tabular}

$\begin{array}{lll}\text { Total Volume } & \left(\mathrm{mm}^{3}\right) \quad 10,28\end{array}$

ILM - RPE Map RPE Surface
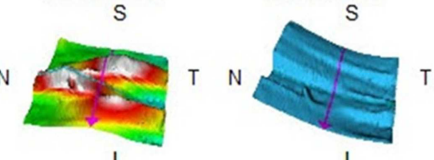


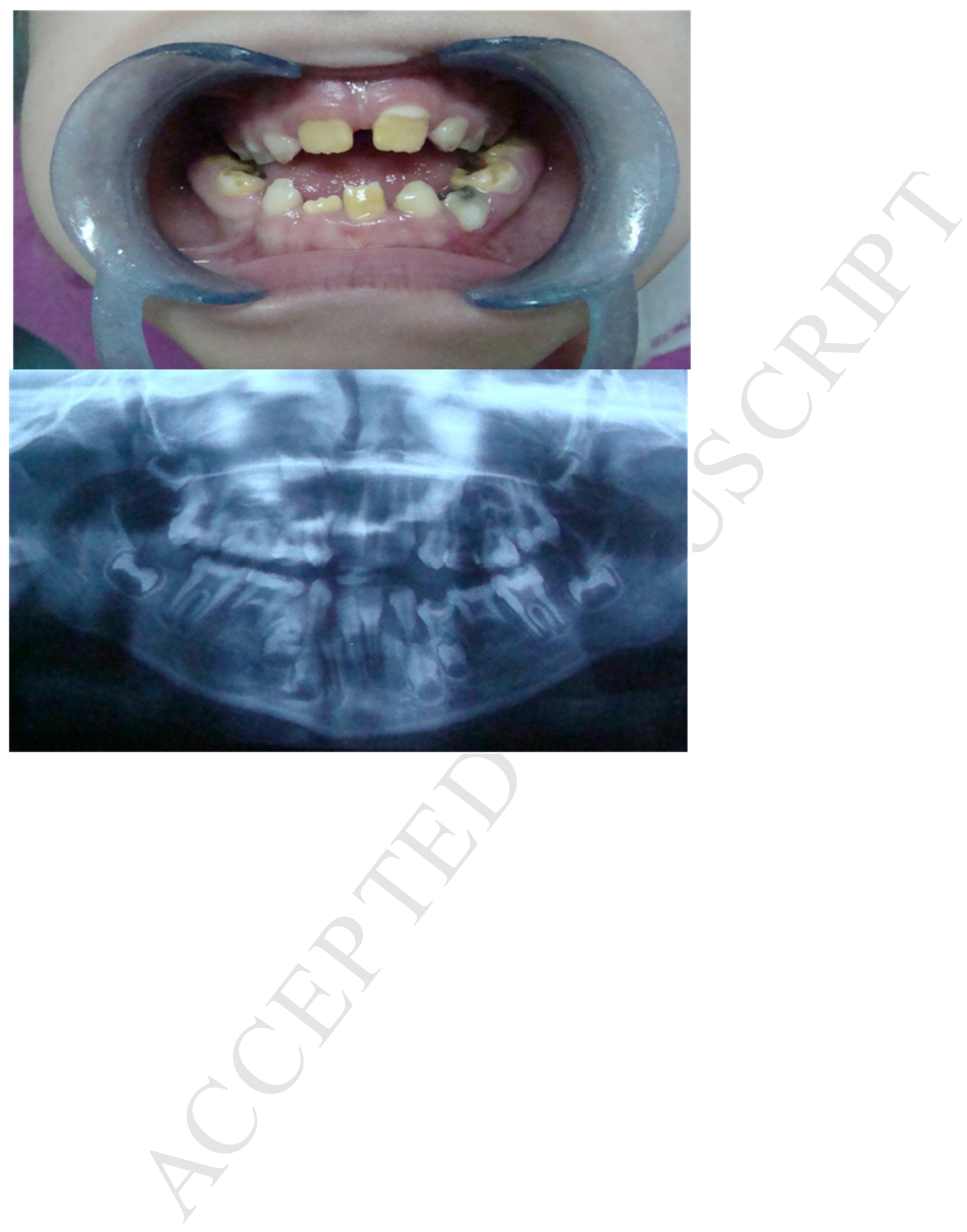




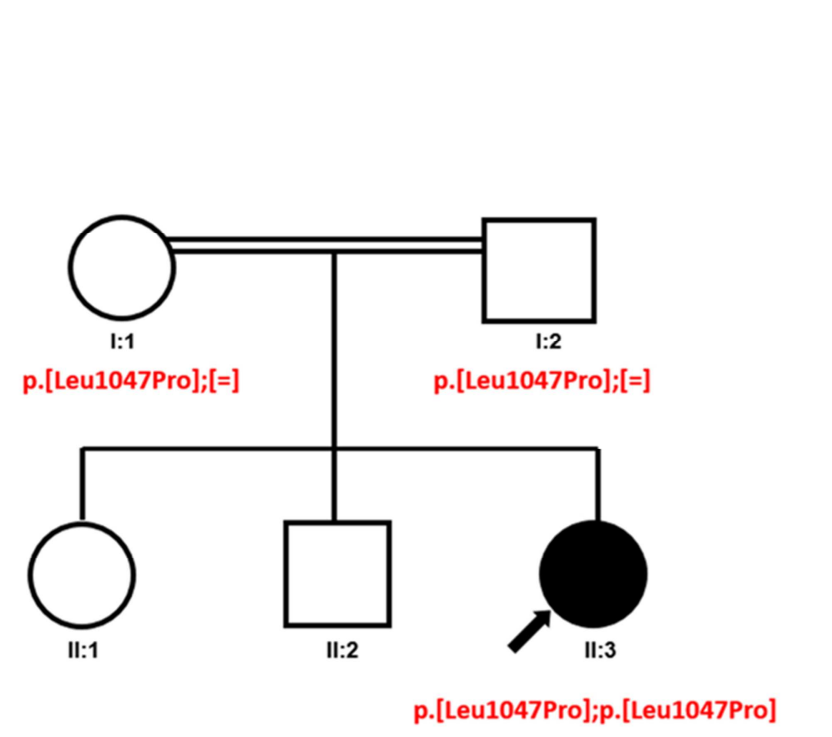

b.

Leu1047Pro

b.

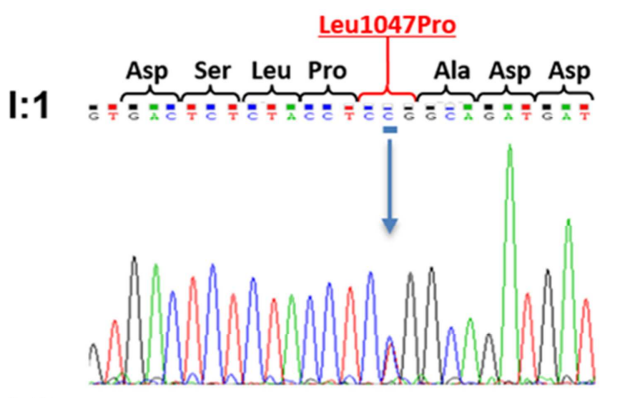

I:2

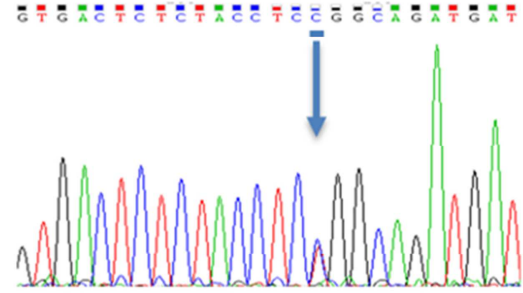

a

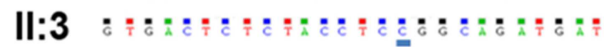

b
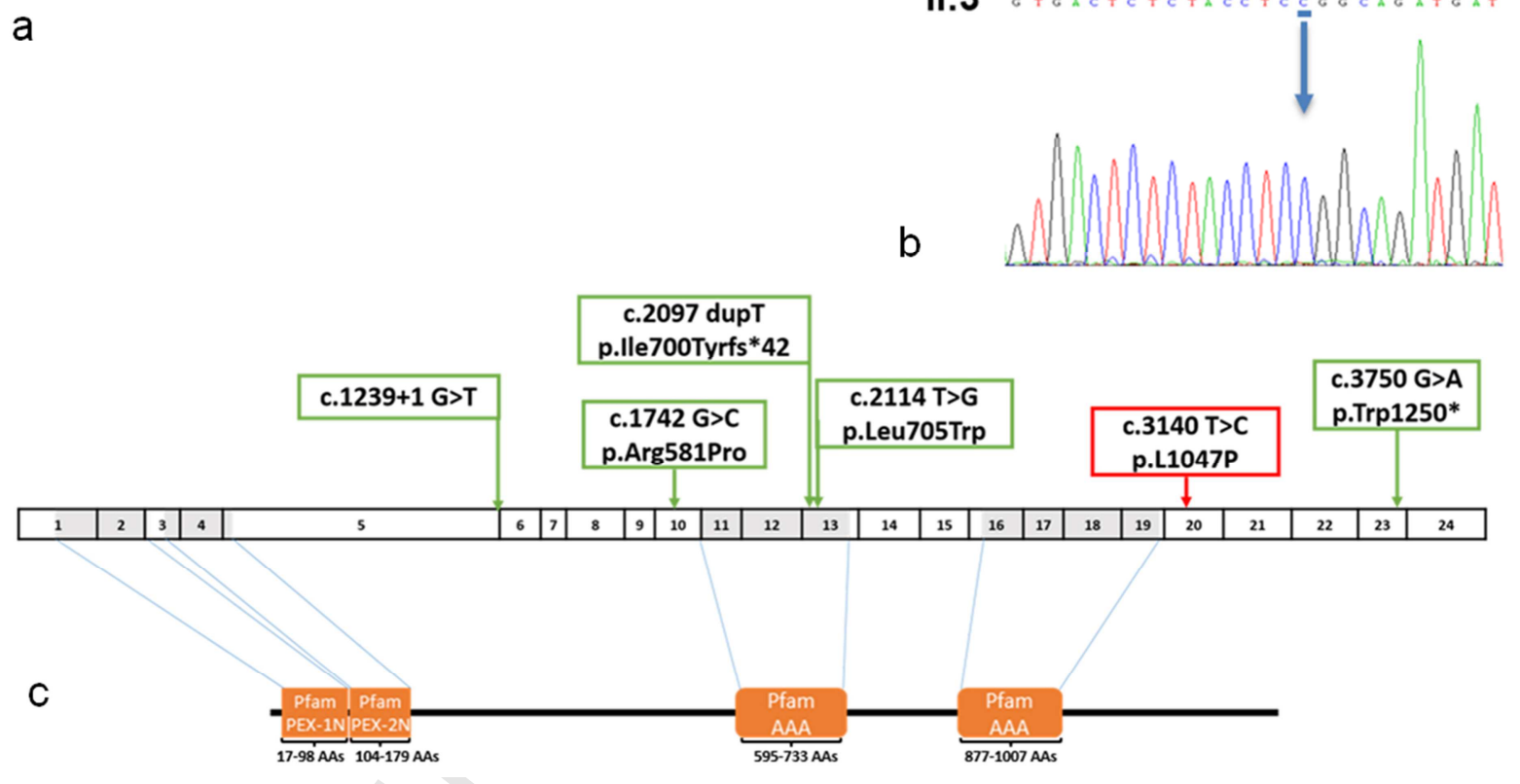